\title{
Water vapor permeation and morphology of polysulfone membranes prepared by phase inversion
}

\author{
Luis Guilherme Macedo Baldo (1), Marcelo Kaminski Lenzi ${ }^{1}$ (i) and Daniel Eiras ${ }^{1 *}$ \\ 1Programa de Pós-graduação em Engenharia Química - PPGEQ, Departmento de Engenharia Química, \\ Universidade Federal do Paraná - UFPR, Curitiba, PR, Brasil \\ *eiras@ufpr.br
}

\begin{abstract}
The aim of this work was to study the effect of different variables in the morphology and water vapor permeation of asymmetric membranes. Different from other works on vapor induced phase inversion this work focus on the formation of a dense skin capable of separating small molecules like gases and on the transport properties of water vapor instead of liquid water. It also correlates the morphologies with the permeability. The results show that higher polymer concentrations lead to denser skin and lower permeability. Water vapor transmission rates varied from 30 to $48 \mathrm{~g} / \mathrm{m}^{2}$.h depending on membrane morphology. They also show that for membranes with the same type of skin layer the permeability depends on the sub-layer. Finally, the results suggest that different mechanisms were responsible for the formation of the membranes.
\end{abstract}

Keywords: asymmetric membranes, vapor induced phase inversion, water vapor permeation.

How to cite: Baldo, L. G. M., Lenzi, M. K., \& Eiras, D. (2020). Water vapor permeation and morphology of polysulfone membranes prepared by phase inversion. Polímeros: Ciência e Tecnologia, 30(3), e2020027. https://doi. org/10.1590/0104-1428.05820

\section{Introduction}

Membranes have been extensively studied and applied for several separations like gas and vapor separations, water production and purification, carbon capture and sequestration among others ${ }^{[1,2]}$. The application of membrane separation processes requires membranes with high flux and selectivity, characteristics that can be tuned not only by changing the properties of the materials that form the membrane, but also by changing the membrane geometry and morphology.

In terms of membrane morphology, asymmetric membranes are usually desired. In the case of gas and vapor separations, a dense separation top layer is supported by a porous layer that is not supposed to impose any resistance to mass transfer. These membranes are produced by the phase inversion process that promotes phase separation of the polymer solution by contacting it with a non solvent (usually water $)^{[3,4]}$. Phase inversion can be triggered by several different processes that include, for example, non solvent induced phase separation (NIPS) ${ }^{[5]}$, vapor induced vapor separation (VIPS) ${ }^{[6]}$ or temperature induced phase separation (TIPS).

Due to its importance in membrane production, phase inversion process has been studied to determine the influence of different variables in the final morphology ${ }^{[7-10]}$. In these studies, different formation mechanisms were proposed to explain the formation of macrovoids, a cellular morphology, and interconnected structure and the dense layer. Among those mechanisms, two of the most recent studies have relied on rheological characterization of the polymer solutions to correlate the final morphology with chain entanglement $t^{[11]}$ and solvent power ${ }^{[12]}$. Depending on the rheological behavior of the solutions that is related to chain entanglement and solvent quality, the final membranes can have macrovoids or a cellular morphology. Because both studies focus on NIPS spinodal decomposition is not discussed.

Other researchers have focused on VIPS trying to correlate the different variables to the final morphology and properties of the membranes ${ }^{[6,13-18]}$. The results showed that solution concentration, relative humidity ${ }^{[16]}$ and time of exposure to the vapor ${ }^{[15]}$ can influence the final morphology. It has also been reported that the choice of solvent can influence the final morphology by reducing the effect of coalescence of pores in membranes formed by spinodal decomposition ${ }^{[13]}$. The mechanism proposed by these authors also depends on rheological properties. Although most of these authors are interested in the porous structure and the application of membranes for liquid separations, their work shows that the coalescence of the pores in membranes formed by spinodal decomposition can create a very thin dense skin that can be applied for gas and vapor separations ${ }^{[13,15,19]}$. Recently, Dai et al. ${ }^{[20]}$ proposed a process that combines VIPS and NIPS to produce membranes for gas separation. By combining the two processes they prevented the formation of pin-holes on the dense layer that can compromise the selectivity of the membrane. The authors argued that vapor induced phase separation can create a sublayer that reduces the mass transfer of both solvent from the membrane and non-solvent from the coagulation bath and protect the dense layer. 
In this context, this work has the objective to characterize membranes prepared by vapor induced phase inversion combined with non-solvent induced phase inversion using different combinations of three variables: polymer concentration, water concentration in the solution and time inside the coagulation bath. The membranes were characterized by scanning electron microscopy (SEM) and water vapor permeation. The results show a correlation between the polymer concentration and water concentration in the solution with the final morphology. It is also possible to correlate the morphology and WVT . The morphology indicates that different mechanisms could explain the formation of the final morpohology. Finally, the results indicate that VIPS has a great potential to be applied in the production of asymmetric membranes with a dense skin for gas separation.

\section{Materials and Methods}

\subsection{Materials}

Polysulfone Udel P-3500® was kindly supplied by SolvayBrazil. 1-methyl-2-pirrolidone (NMP-anhydrous, 99.5\%) from Sigma-Aldrich was used as solvent for polysulfone. Ethanol (PA, 99.5\%) and hexane (PA, 99.5\%) from Synth were used for solvent exchange and tapped water was used as non-solvent and additive.

\subsection{Methods}

Polysulfone/NMP solutions were prepared by dissolving different concentrations of the polymer in the solvent. Polysulfone and NMP were mixed in a laboratory glass bottle that was closed and placed on a roller mixer. Complete dissolution was observed after 2 or 3 days depending on polymer concentration. The polymer concentrations used were 15,25 and $35 \mathrm{wt} \%$. Some solutions were prepared using water as additive. The water concentrations were 0 , 2.5 and 5 vol. \% in relation to the solvent initial volume. Table 1 shows the compositions and process conditions used to produce each sample.

The membranes were prepared using a combination of non-solvent induced phase separation and vapor induced

Table 1. Polymer concentrations and process variables used for membrane preparation.

\begin{tabular}{cccc}
\hline Sample & $\begin{array}{c}\text { Polysulfone } \\
\text { (PSF) } \\
\text { concentration } \\
(\mathbf{w t} \%)\end{array}$ & $\begin{array}{c}\text { Time in } \\
\text { coagulation } \\
\text { bath (min.) }\end{array}$ & $\begin{array}{c}\text { Water } \\
\text { concentration } \\
\text { (vol\%) }\end{array}$ \\
\hline 1 & 35 & 60 & 2.5 \\
2 & 35 & 10 & 2.5 \\
3 & 15 & 60 & 2.5 \\
4 & 15 & 10 & 2.5 \\
5 & 35 & 35 & 5.0 \\
6 & 35 & 35 & 0.0 \\
7 & 15 & 35 & 5.0 \\
8 & 15 & 35 & 0.0 \\
9 & 25 & 60 & 5.0 \\
10 & 25 & 60 & 0.0 \\
11 & 25 & 10 & 5.0 \\
12 & 25 & 10 & 0.0 \\
13 & 25 & 35 & 2.5 \\
\hline
\end{tabular}

phase separation. The polymer solutions were cast on a glass plate using a casting knife. Then the membrane was exposed to water vapor for 5 minutes inside an oven at $40{ }^{\circ} \mathrm{C}$. The relative humidity inside the oven was kept between 40 and $60 \%$ during exposure. After the water vapor exposure, the membrane was immersed in the coagulation bath to complete phase inversion.

The membranes were kept inside the coagulation bath for different periods of time varying from 10 to 60 minutes. Afterwards, the membranes were dried by soaking the membrane in ethanol for 24 hours and then soaking in hexane followed by drying in a vaccum oven at $68^{\circ} \mathrm{C}$ for $24 \mathrm{~h}$.

The morphology of the membranes was characterized by scanning electron microscopy analysis (SEM) in a JEOL JSM 6360-LV microscope. Criofractured samples were tested to evaluate the porous structure of the sublayer while the surface of the membranes was analyzed to verify the intregrity of the top layer.

Water vapor permeation tests were conducted according to ASTM E96/E96M standard ${ }^{[21]}$. In a typical procedure, a cylindrical cup filled with water was covered by the membranes. The initial weight of the cups were measured and compared to their weight at different periods of time. Water vapor transmission (WVT) was calculated with Equation 1.

$$
W V T=\frac{G}{t \cdot A}
$$

In Equation $1 \mathrm{G}$ is the weigth change, $\mathrm{t}$ is the time and $\mathrm{A}$ is the permeation area.

\section{Results and Discussions}

\subsection{Effect of water vapor activity}

Water vapor activity can be calculated by the ratio between the partial pressure of water and the equilibrium vapor pressure which makes the activity equivalent to the relative humidity. The activity of water vapor can influence the phase inversion in two different forms. First, the onset of VIPS is influenced by water vapor activity. It has been reported that phase separation induced by water vapor is observed for relative humidities of $65 \%$ or higher $\left(a_{w} \geq 0.65\right)^{[16]}$. Second, the activity gradient through the membrane thickness influences mass transport of water and solvent exchange. Because the activity of water in the vapor phase is considered equivalent to the activity in liquid water, the differences between VIPS and NIPS are due to differences in mas transfer coefficients ${ }^{[6,16,17,19]}$. Different activity gradients can lead to different morphologies like symmetrical cellular morphology, asymmetrical cellular morphology or finger like pores. In the present work the relative humitidity range was between $40-60 \%$ which represents activities of $0.40-0.60$. The change in humidity is due to the loss of water vapor that results from opening the oven to cast membranes and some variations in the oven temperature. Despite the lower activity there is evidence of phase separation by VIPS which could be due to the presence of water in the polymer solutions. Based on the morphologies of the membranes, we believe that the water vapor activity inside the oven might have influenced the onset 
of VIPS and the morphology of samples 4 and 10 leading to NIPS (Sample 10) or a combination of NIPS and VIPS (Sample 4). In the other samples it is more likely that the morphology was influenced by the mass transport of the non-solvent than the onset of phase separation. In that case, the range of relative humidity had a minor influence or no influence in the final morphology.

\subsection{Morphology and phase inversion mechanism.}

\subsubsection{Typical morphologies obtained in this work.}

Figures 1-3 show the typical morphologies that were obtained in this work. Figure 1 shows the morphology of samples resulting from spinodal decomposition. This morphology is obtained when the membrane composition crosses the spinodal line ${ }^{[6,15]}$, being an interconnected combination of pores and fibrils that looks like a deformed material. It is also obtained in the early stages of vapor induced phase inversion and usually coalesce over time to reduce the surface tension of the porous structure ${ }^{[13,15]}$. In the case of the membranes in Figure 1, coalescence is similar to previously reported results ${ }^{[13,15,16]}$ considering the long time of vapor exposure (5 minutes) and it probably explains the lack of pore conectivity.

Figure 2 presents the surface of these membranes, which show one dense surface and three porous surfaces. The dense surface is obtained due to coalescence of the previous spinodal structure that starts on the air (vapor)/ membrane surface and is favored by the increase of the concentration of polymer in solution ${ }^{[15]}$. In Figure 2, the denser morphology was obtained from a $35 \mathrm{wt} \%$ solution.

Figure 3 shows a cellular morphology and some interconnected pores that are characteristic of spinodal decomposition. The cellular morphology results from the slow diffusion of non-solvent through the cross section of polymer solution that makes the concentration gradient negligible in the cross section ${ }^{[6,17]}$. In the case of the membranes in Figure 3, the final morphology can be the result of spinodal decomposition that takes place in the some parts of the membrane and nucleation and growth to form the cellular morphology. The membrane surfaces in Figure 3 shows that a very thin dense layer was created which can reduce the diffusion of water vapor and create a cellular morphology specially at longer distances from the air interface ${ }^{[6]}$.

Figure 4 shows typical symmetric cellular morphology. The symmetric cellular morphology without interconnected pores indicate that phase separation takes place while the solution composition is in the metastable region between spinodal and binodal ${ }^{[5,15,22]}$. In this case, the morphology results from nucleation and growth. At the same time, the dense layer in Figure $4 d$ and the small pores in Figure $4 \mathrm{c}$ suggest that spinodal decomposition and coalescence took place closer to the air (water vapor) interface.

Figure 5 shows the morphology of two membranes with macrovoids in their cross section. The morphology in Figure 5a seems to result from spinodal decomposition that has not reached the end of membrane thickness combined
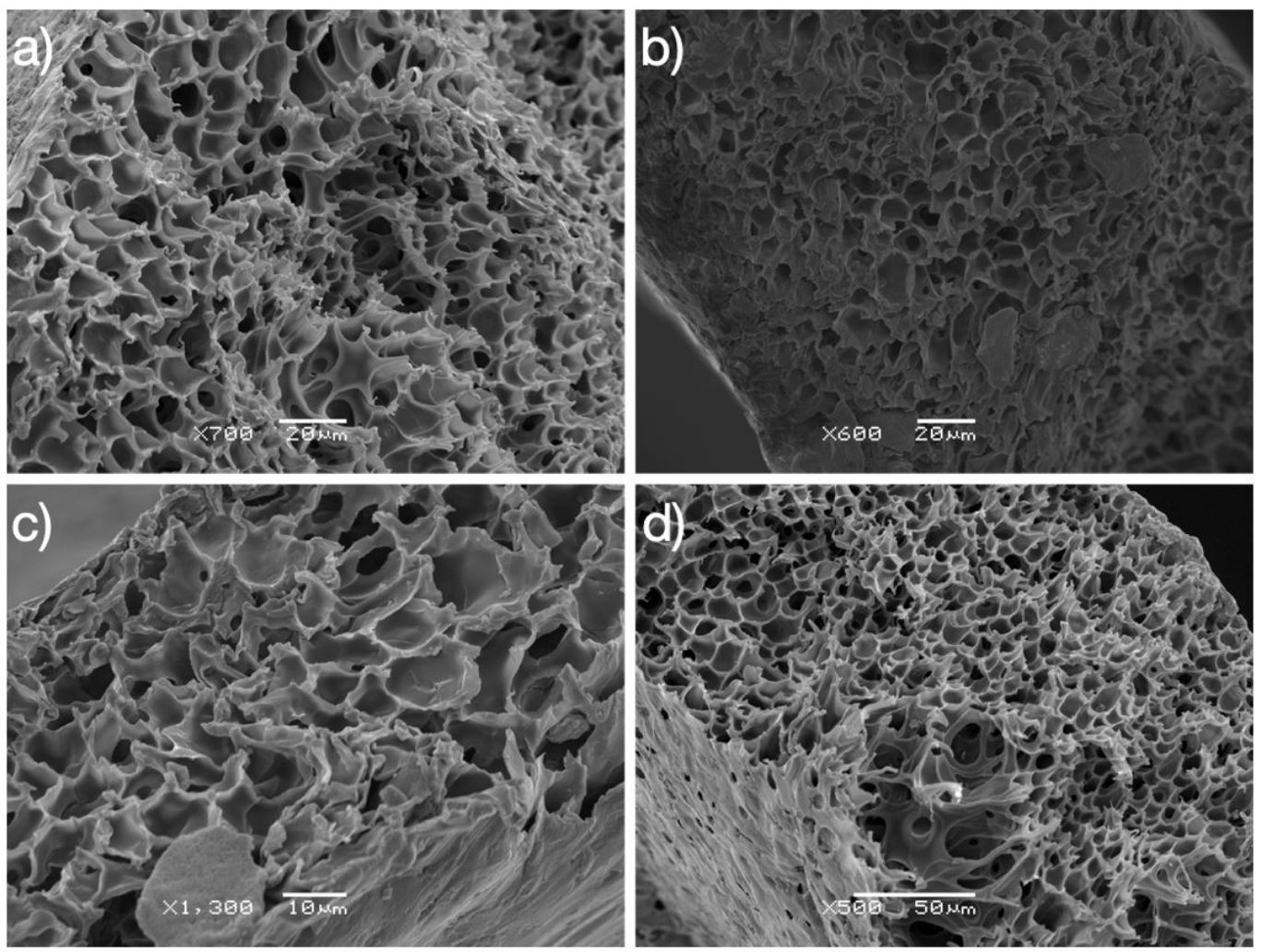

Figure 1. Cross-section of spinodal morphologies. (a) Sample 5 (35 wt $\% \mathrm{PSF} / 35 \mathrm{~min} . / 5$ vol. $\%$ water); (b) Sample 7 (15 wt $\% \mathrm{PSF} / 35 \mathrm{~min} . / 5$ vol.\%water); (c) Sample 8 (15 wt\%PSF/35 min./0 vol.\%water); (d) Sample 9 (25 wt\%PSF/1 min./5 vol.\%water). 


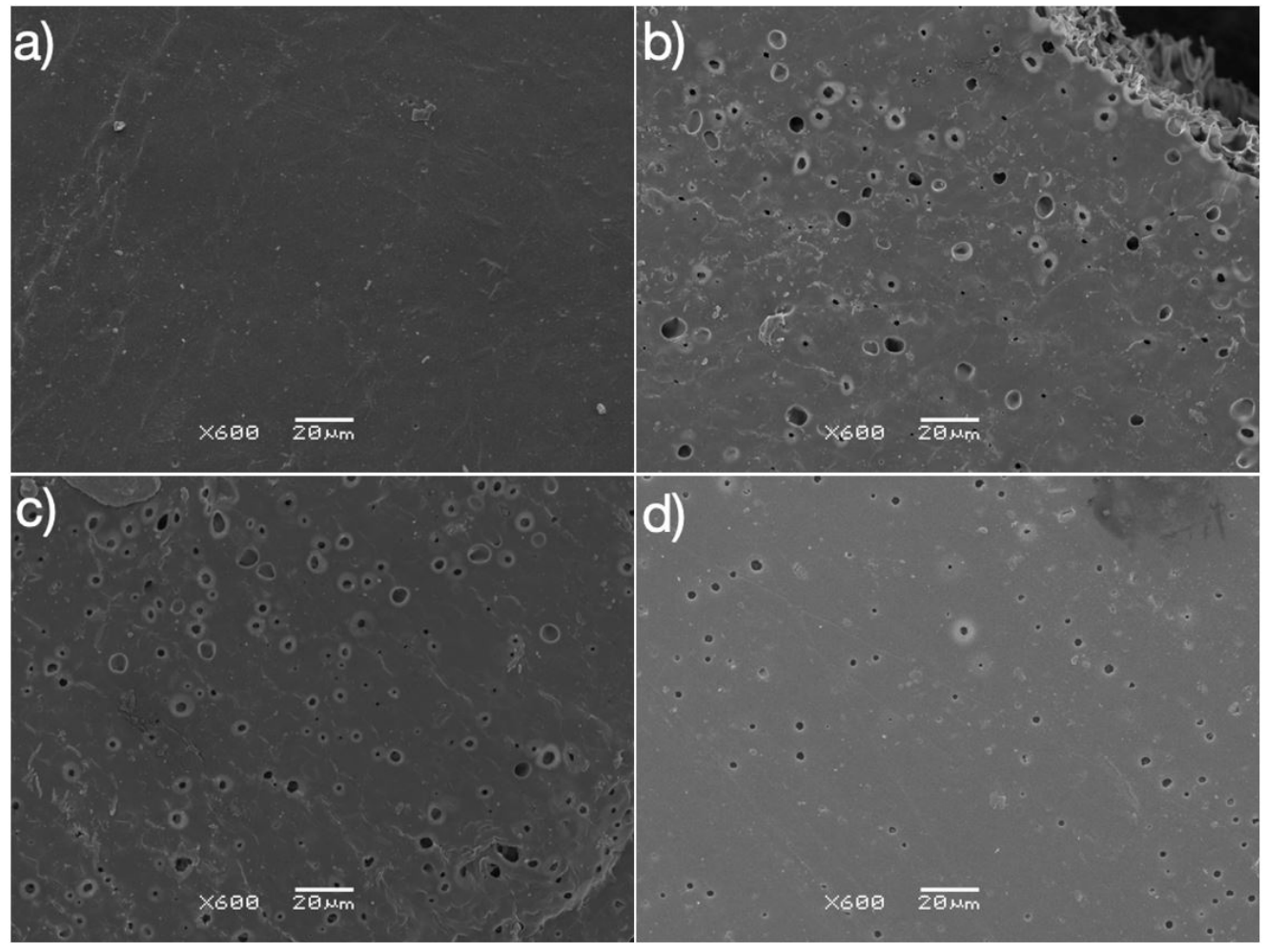

Figure 2. Surface morphologies of membranes shown in Figure 1. (a) Sample 5 (35 wt $\%$ PSF $/ 35$ min. $/ 5$ vol.\%water); (b) Sample 7 (15 wt \%PSF/35 min./5 vol.\%water); (c) Sample 8 (15 wt\%PSF/35 min./0 vol.\%water); (d) Sample 9 (25 wt\%PSF/1 min./5 vol.\%water).

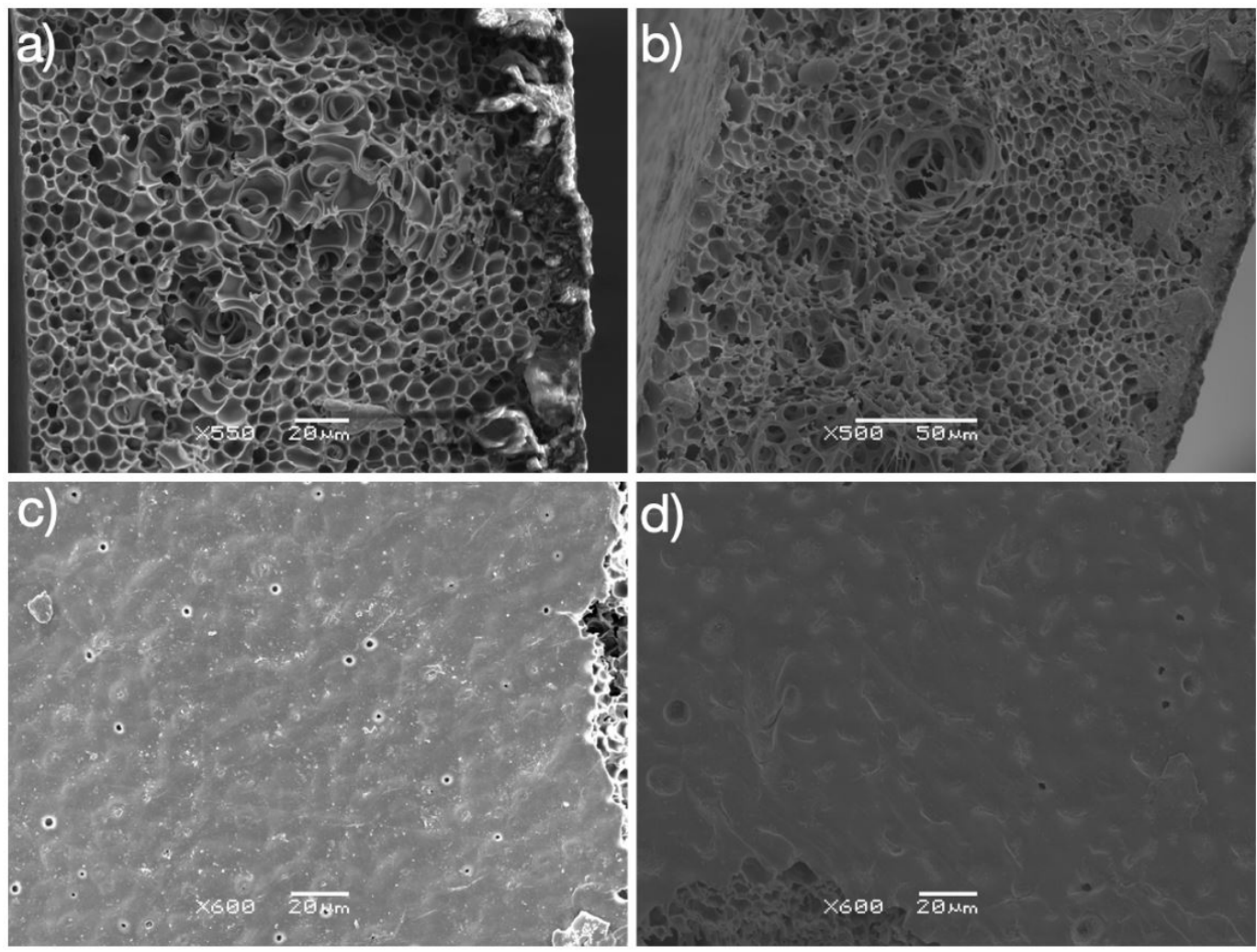

Figure 3. Morphologies of typical asymmetric cellular morphology. (a) and (c) Sample 6 (35 wt\%PSF/35 min./0 vol.\%water); (b) and (d) Sample 12 (25 wt\%PSF/10 min./0 vol.\%water). 


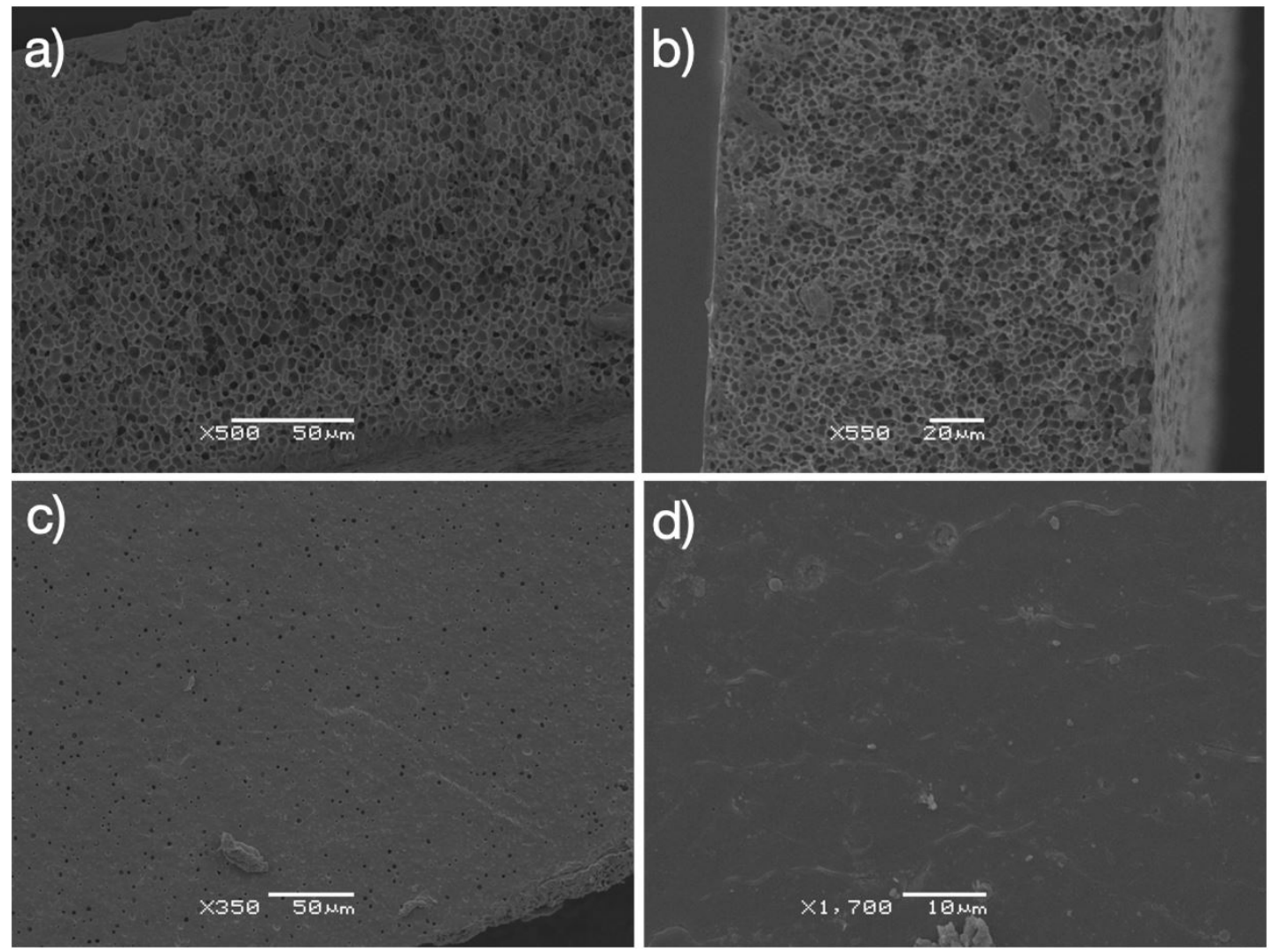

Figure 4. Symmetric cellular morphology. (a) and (c) Sample 11 (25 wt\%PSF/10 min./0 vol.\%water); (b) and (d) Sample 13 (25 wt $\% \mathrm{PSF} / 35 \mathrm{~min} . / 1$ vol.\%water).
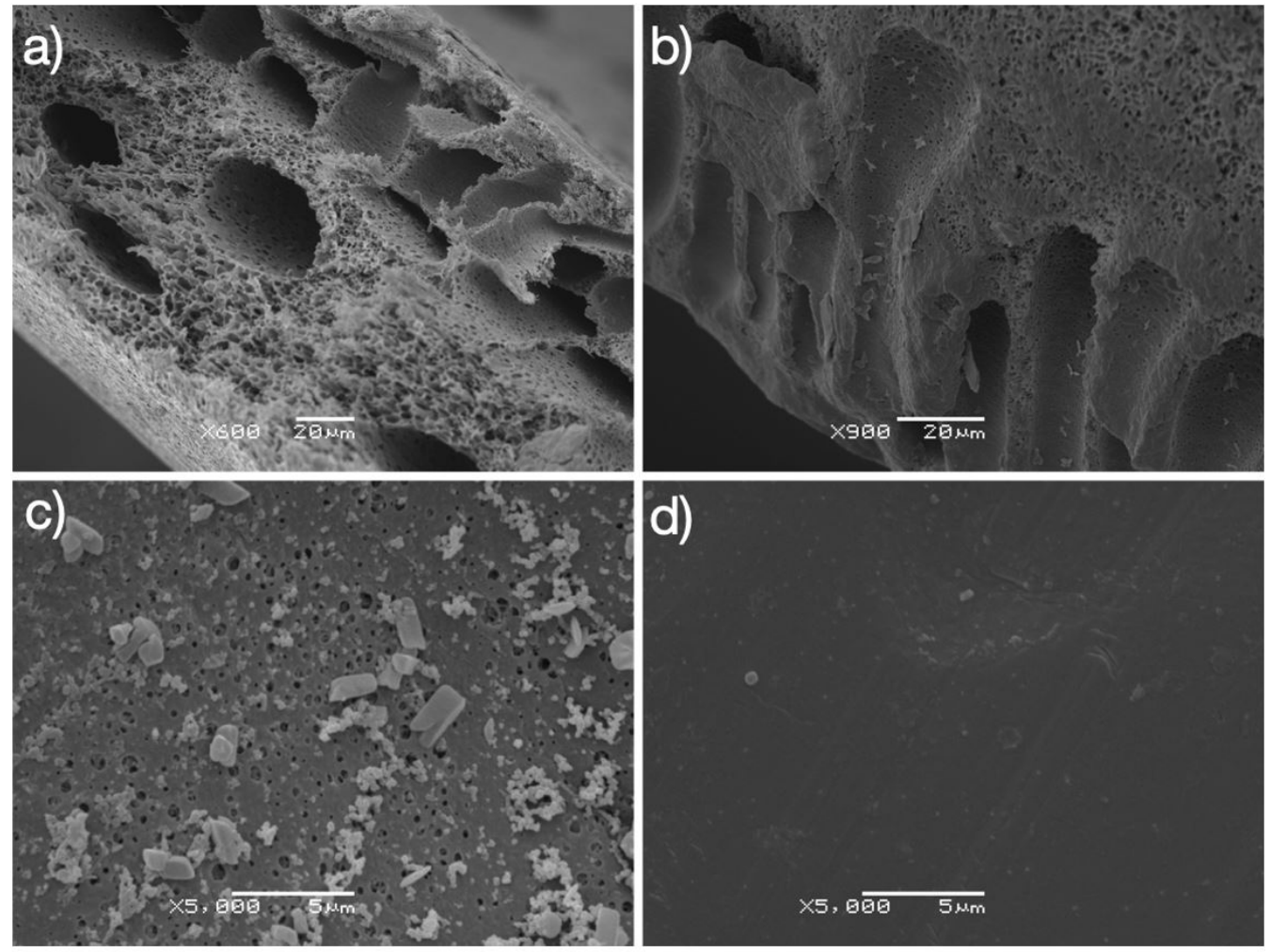

Figure 5. Cross section and surface of membranes having macrovoids. (a) and (c) Sample 4 (15 wt $\% \mathrm{PSF} / 10 \mathrm{~min} . / 2,5$ vol.\%water); (b) and (d) Sample 10 (25 wt \%PSF/1 min./0 vol.\%water). 
with phase inversion due to non solvent induced phase separation that resulted in elongated finger-like pores ${ }^{[6,10-12,15]}$. The fact that the surface of the membrane still have pores corroborates with the statement that spinodal decomposition took place. In Figure 5b, the morphology is almost entire formed by non solvent induced phase separation, i.e the water vapor exposure did not result in phase inversion and the final morphology was formed after immersion in water. The dense skin without apparent pores or pin holes is characteristic of immersion precipitation membranes.

\subsubsection{Effect of polymer concentration on membrane morphology}

The polymer concentration in solution is an important variable in phase inversion processes ${ }^{[4,10-12]}$. Increasing the concentration increases the viscosity and reduces the rate of solvent/non solvent exchange ${ }^{[10]}$. The effect of viscosity relates to chain entanglement and relaxation times ${ }^{[1]}$. For PSF/ NMP systems it has been reported that there is a transition in zero shear rate viscosity with the increase in concentration. This transition is observed around $23 \mathrm{wt} \%$ of PSF in NMP and is characterized by a critical entanglement concentration above which the polymer behaves more like a solid than like a liquid ${ }^{[11]}$. According to that theory, phase separation will take place only when the polymer behaves like a liquid which means that for concentrated solutions the final morphology will depend on the relation between the relaxation time and the time for phase inversion. In the case of vapor induced phase separation at higher concentrations the distance between the binodal line and spinodal line increases which means that it takes more water vapor to take the solution concentration to the decomposition zone and for spinodal decomposition to start ${ }^{[15]}$. As a result spinodal decomposition might not be observed in concentrated solutions or more likely it will be observed on the surface of the solution that is close to water vapor. This last statement explains the effect of polymer concentration in the morphologies in Figure 6.
For the membrane prepared from a $15 \mathrm{wt} \%$ solution, it is possible to observe a deformed morphology that is characteristic of spinodal decomposition ${ }^{[6,15,17,18]}$. For higher concentrations the final morphology is a cellular morphology that is usually associated with nucleation and growth ${ }^{[6,15]}$. When analyzing the surfaces of these membranes it is clear that for the membrane prepared from the $15 \mathrm{wt} \%$ solution there is a series of pores that are formed due to coalescence of the spinodal morphology. For higher concentrations, it is possible to observe a denser layer which can only be formed by VIPS during coalescence of spinodal morphology ${ }^{[6,15]}$. The formation of a denser skin influences the final morphology of VIPS membranes because it reduces water vapor diffusion to the inside of the solution and keeps the solution in the meta stable zone for longer periods of time which favors the nucleation and growth mechanism over spinodal decomposition ${ }^{[15]}$.

\subsubsection{Effect of water on membrane morphology}

The addition of water to the polymer solution is not recommended in real applications because it makes it difficult to dissolve the polymer but it can be used to evaluate other effects of the phase inversion process in membrane morphology. As a non solvent water increases the viscosity of the solution and also favors the formation of entanglement which reduces the critical entanglement concentration and increases relaxation time ${ }^{[11]}$. It is also expected that the presence of water in the polymer solutions reduces the amount of water vapor that is necessary to induce spinodal decomposition and also reduces the mass transfer rate of water vapor to the solution. Figure 7 shows the morphology of the membranes prepared with the addition of $5 \mathrm{vol} \%$ of water.

The amount of water that was added to these solutions is enough to bring the concentration very close to the binodal line which means that a small amount of vapor would be
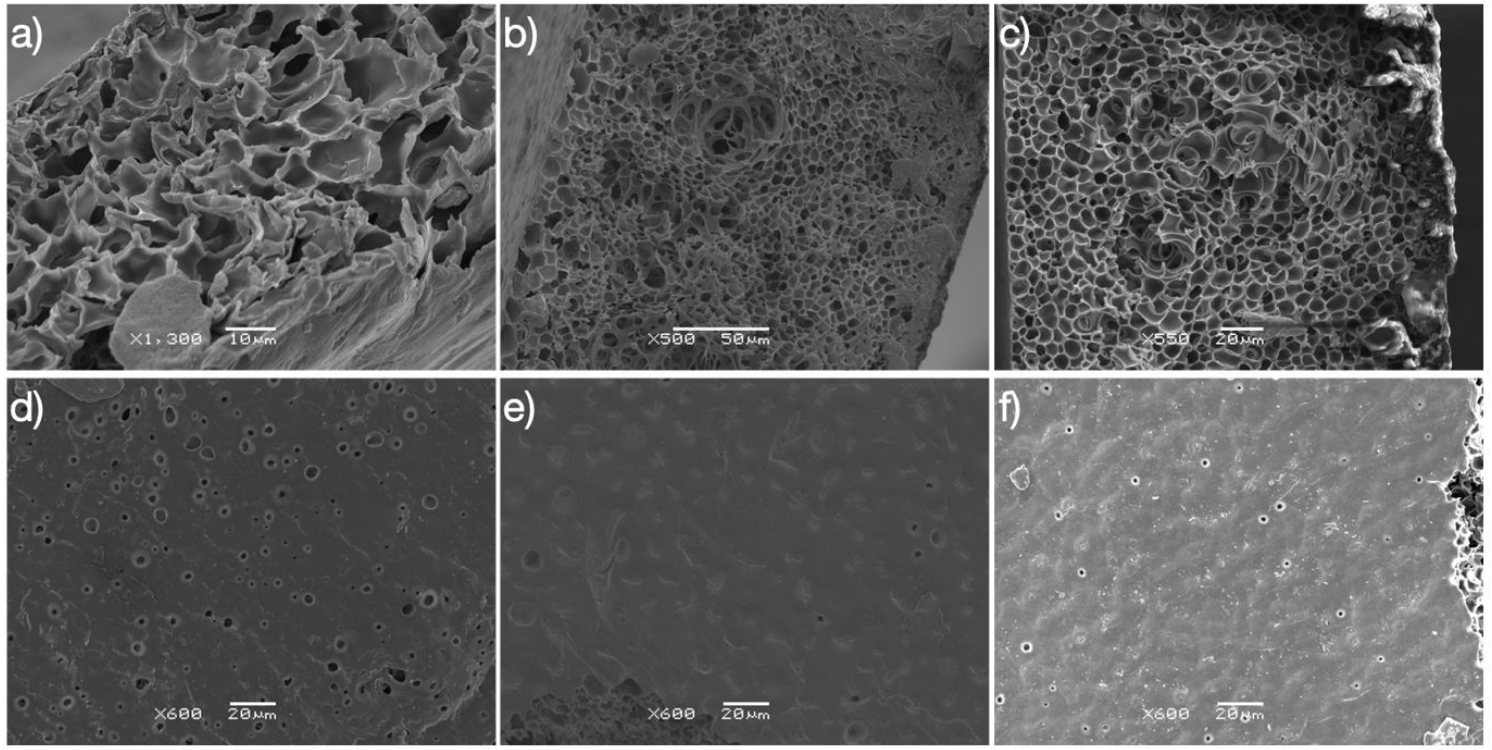

Figure 6. Effect of polymer concentration on membrane morphology. (a) and (d) Sample 8 (15 wt\%PSF/35 min./0 vol.\%water); (b) and (e) Sample 12 (25 wt\%PSF/10 min./0 vol.\%water); (c) and (f) Sample 6 (35 wt\%PSF/35 min./0 vol.\%water). 

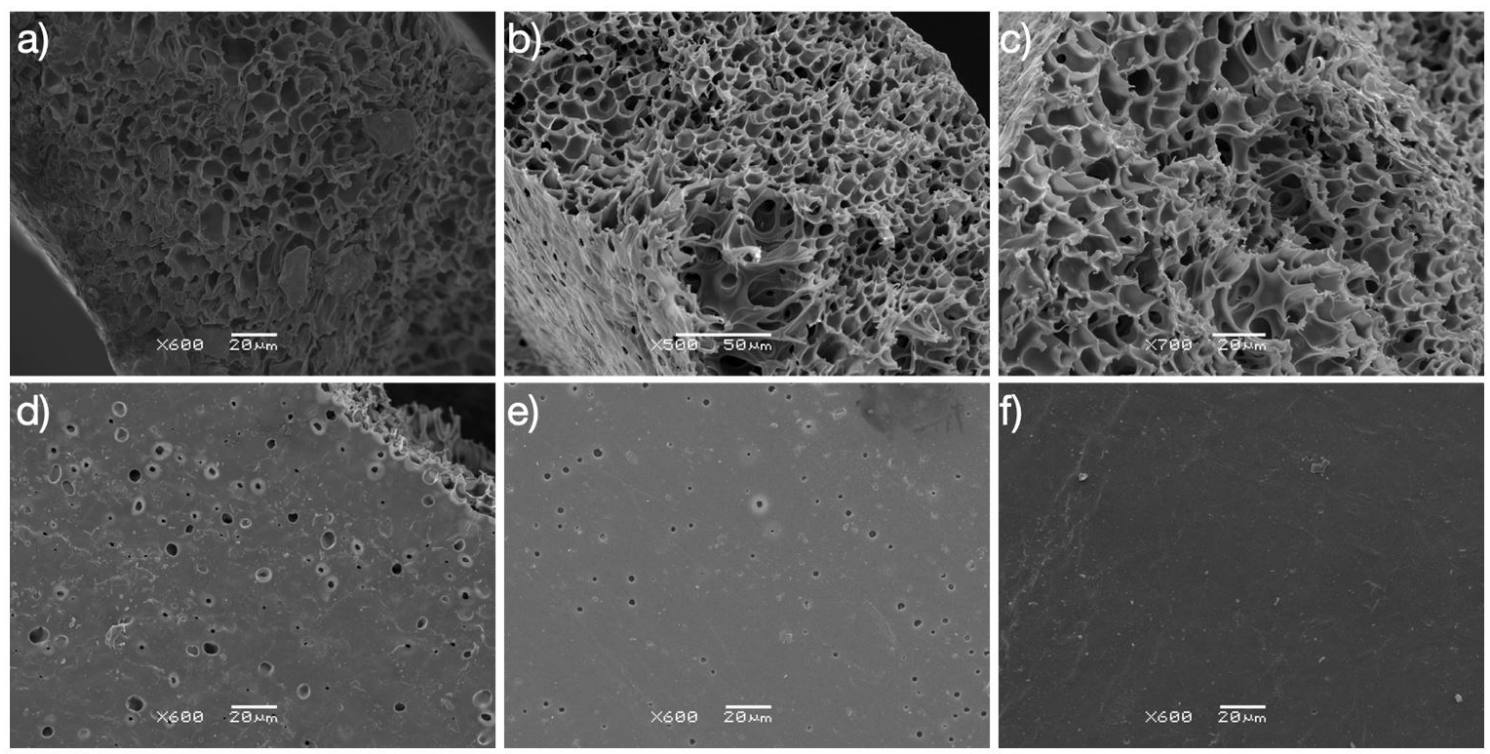

Figure 7. Effect of water in the morphology. (a) and (d) Sample 7 (15 wt $\%$ PSF $/ 35$ min. $/ 5$ vol.\%water); (b) and (e) Sample 9 ( 25 wt $\%$ PSF $/ 1$ min. $/ 5$ vol. \%water); (c) and (f) Sample 5 (35 wt\%PSF/35 min. $/ 5$ vol.\%water).

Table 2. Water vapor transmission (WVT) of Polysulfone membranes.

\begin{tabular}{|c|c|c|c|}
\hline $\begin{array}{l}\text { Sample } \\
\text { Number }\end{array}$ & $\begin{array}{c}\text { Morphology } \\
\text { (Cross-section) }\end{array}$ & $\begin{array}{l}\text { Morphology } \\
\text { (Top-Layer) }\end{array}$ & $\begin{array}{c}\text { WVT } \pm \\
\text { Standard } \\
\text { Deviation } \\
\left(\mathrm{g} / \mathrm{m}^{2} . \mathbf{h}\right)\end{array}$ \\
\hline 1 & \multirow{6}{*}{$\begin{array}{l}\text { Lacy -Spinodal } \\
\text { Decomposition }\end{array}$} & Dense (very thin) & 41 \\
\hline 3 & & Dense (very thin) & $41 \pm 3.4$ \\
\hline 5 & & Dense & $27 \pm 2.6$ \\
\hline 7 & & Porous & $44 \pm 3.5$ \\
\hline 8 & & Porous & $44 \pm 0.3$ \\
\hline 9 & & Porous & $45 \pm 2.1$ \\
\hline 2 & \multirow{5}{*}{$\begin{array}{c}\text { Cellular - } \\
\text { Nucleation and } \\
\text { Growth }\end{array}$} & Porous & $41 \pm 4.8$ \\
\hline 6 & & Dense (pin-holes) & 33 \\
\hline 11 & & Porous & $41 \pm 0.5$ \\
\hline 12 & & Dense (pin-holes) & $37 \pm 2.0$ \\
\hline 13 & & Dense & $30 \pm 2.0$ \\
\hline 4 & \multirow{2}{*}{$\begin{array}{l}\text { Macrovoids - } \\
\text { NIPS }\end{array}$} & Porous & $48 \pm 4.8$ \\
\hline 10 & & Dense & $40 \pm 2.1$ \\
\hline
\end{tabular}

necessary to trigger phase separation. As a result of the incorporation of water to the solution we can observe the spinodal morphology in all the samples. These results suggest that the incorporation of water favors spinodal decomposition but it also reduces, but does not prevent, the effect of coalescence that is usually observed after long periods of exposure to water vapor specially in concentrated solutions. Although it is possible to observe that the effect of coarsening is reduced, the pore connectivity is still compromised which is expected for PSF/NMP solutions because the addition of water to the solution does not increase the viscosity enough to substantially reduce the domain growth rate ${ }^{[11,12]}$. From the surfaces of the membranes, it is observed that higher polymer concentration leads to denser skin layer which is a result of coarsening. Although that might seem controverse, it is important to understand that coarsening is more likely to take place closer to the vapor surface which explains why there are still signs of lacy morphology in the cross section of the membrane. The morphology in Figure $7 f$ indicates that it is possible to obtain a dense skin layer using VIPS which is an important discovery for applications like gas and vapor separations.

\subsection{Water vapor transmission of PSF membranes}

Table 2 shows water vapor transmission (WVT) of the membranes. The results are organized to group the membranes with similar morphology. The results suggest that the membranes with similar morphology have approximate the same WVT. It is possible to deduce from the resuls that the presence of a dense skin-layer decreases WVT. For the sample that presents a lacy like morphology and a porous surface WVT is approximately $45 \mathrm{~g} / \mathrm{m}^{2}$.h (samples 7 , 8 and 9) while sample 5 that has a dense skin-layer has a WVT of $27 \mathrm{~g} / \mathrm{m}^{2}$.h. Samples 6,7 and 10 are other examples of membranes with dense layer and lower permeability. Besides the effect of the dense layer the results show that the porous structure influences WVT. Based on the results the WVT increases in the sequence cellular morphology $<$ lacy morphology $<$ macropores.

The different morphologies and their properties are an important result for the application of VIPS to produce asymmetric membranes for gas and vapor permeation. Usually, this method is used to produce porous membranes that are applied in liquid separation but the results suggest that it might be used to produce asymmetric membranes.

\section{Conclusions}

Asymmetric membranes were produced by a combination of two different phase inversion methodologies and a variety of membrane morphologies were obtained depending on polymer and 
water concentration in the solution that formed the membranes. The results show that vapor induced phase separation (VIPS) can be applied to produce asymmetric membranes with a dense skin layer and that higher polymer concentrations favors the densification of the skin. The incorporation of water in the polymer solution seem to change the phase separation mechanism from nucleation and growth to spinodal decomposition for all the samples. Water vapor permeation tests show that there is a correlation between water vapor transmission and the membrane morphology. The results suggest that different phase inversion mechanisms result from different compositions in the solution and create different morphologies.

\section{Acknowledgements}

The authors acknowledge the support from the Coordenação de Aperfeiçoamento de Pessoal de Nível Superior (CAPES) for the scholarship. From the Conselho Nacional de Pesquisa (CNPq) project 420696/2018-0, and Solvay Specialty Polymers for supplying the polymer Udel $\mathrm{P}-3500 \AA$ that was used as matrix for membrane formation.

\section{References}

1. Kárászová, M., Zach, B., Petrusová, Z., Červenka, V., Bobák, M., Šyc, M., \& Izák, P. (2020). Post-combustion carbon capture by membrane separation, review. Separation and Purification Technology, 238, 116448-116456. http://dx.doi.org/10.1016/j. seppur.2019.116448.

2. Nunes, S. P., Culfaz-Emecen, P. Z., Ramon, G. Z., Visser, T., Koops, G. H., Jin, W., \& Ulbricht, M. (2020). Thinking the future of membranes: perspectives for advanced and new membrane materials and manufacturing processes. Journal of Membrane Science, 598, 117761-117788. http://dx.doi. org/10.1016/j.memsci.2019.117761.

3. Li, Y., Cao, B., \& Li, P. (2019). Effects of dope compositions on morphologies and separation performances of PMDA-ODA polyimide hollow fiber membranes in aqueous and organic solvent systems. Applied Surface Science, 473, 1038-1048. http://dx.doi.org/10.1016/j.apsusc.2018.12.245.

4. Kausar, A. (2017). Phase inversion technique-based polyamide films and their applications: a comprehensive review. PolymerPlastics Technology and Engineering, 56(13), 1421-1437. http://dx.doi.org/10.1080/03602559.2016.1276593.

5. Hołda, A. K., \& Vankelecom, I. F. J. (2015). Understanding and guiding the phase inversion process for synthesis of solvent resistant nanofiltration membranes. Journal of Applied Polymer Science, 132(27), 1-17. http://dx.doi.org/10.1002/app.42130.

6. Ismail, N., Venault, A., Mikkola, J. P., Bouyer, D., Drioli, E., \& Tavajohi Hassan Kiadeh, N. (2020). Investigating the potential of membranes formed by the vapor induced phase separation process. Journal of Membrane Science, 597, 117601-117636. http://dx.doi.org/10.1016/j.memsci.2019.117601.

7. Ismail, A. F., \& Lai, P. Y. (2003). Effects of phase inversion and rheological factors on formation of defect-free and ultrathin-skinned asymmetric polysulfone membranes for gas separation. Separation and Purification Technology, 33(2), 127-143. http://dx.doi.org/10.1016/S1383-5866(02)00201-0.

8. Guillen, G. R., Pan, Y., Li, M., \& Hoek, E. M. V. (2011). Preparation and characterization of membranes formed by nonsolvent induced phase separation: a review. Industrial \& Engineering Chemistry Research, 50(7), 3798-3817. http:// dx.doi.org/10.1021/ie101928r.

9. Xiang, J., Hua, X., Dong, X., Cheng, P., Zhang, L., Du, W., \& Tang, N. (2019). Effect of nonsolvent additives on PES ultrafiltration membrane pore structure. Journal of Applied Polymer Science, 136(15), 1-8. http://dx.doi.org/10.1002/app.47525.

10. Smolders, C. A., Reuvers, A. J., Boom, R. M., \& Wienk, I. M. (1992). Microstructures in phaseinversionmembranes. 1. Formation of macrovoids. Journal of Membrane Science, 73(23), 259-275. http://dx.doi.org/10.1016/0376-7388(92)80134-6.

11. Hung, W. L., Wang, D. M., Lai, J. Y., \& Chou, S. C. (2016). On the initiation of macrovoids in polymeric membranes: effect of polymer chain entanglement. Journal of Membrane Science, 505, 70-81. http://dx.doi.org/10.1016/j.memsci.2016.01.021.

12. Mousavi, S. M., \& Zadhoush, A. (2017). Investigation of the relation between viscoelastic properties of polysulfone solutions, phase inversion process and membrane morphology: the effect of solvent power. Journal of Membrane Science, 532, 47-57. http://dx.doi.org/10.1016/j.memsci.2017.03.006.

13. Tsai, J. T., Su, Y. S., Wang, D. M., Kuo, J. L., Lai, J. Y., \& Deratani, A. (2010). Retainment of pore connectivity in membranes prepared with vapor-induced phase separation. Journal of Membrane Science, 362(1-2), 360-373. http://dx.doi. org/10.1016/j.memsci.2010.06.039.

14. Peng, Y., Dong, Y., Fan, H., Chen, P., Li, Z., \& Jiang, Q. (2013). Preparation of polysulfone membranes via vapor-induced phase separation and simulation of direct-contact membrane distillation by measuring hydrophobic layer thickness. Desalination, 316 , 53-66. http://dx.doi.org/10.1016/j.desal.2013.01.021.

15. Su, Y. S., Kuo, C. Y., Wang, D. M., Lai, J. Y., Deratani, A., Pochat, C., \& Bouyer, D. (2009). Interplay of mass transfer, phase separation, and membrane morphology in vapor-induced phase separation. Journal of Membrane Science, 338(1-2), 17-28. http://dx.doi.org/10.1016/j.memsci.2009.03.050.

16. Chae Park, H., Po Kim, Y., Yong Kim, H., \& Soo Kang, Y. (1999). Membrane formation by water vapor induced phase inversion. Journal of Membrane Science, 156(2), 169-178. http://dx.doi.org/10.1016/S0376-7388(98)00359-7.

17. Tsai, H. A., Kuo, C. Y., Lin, J. H., Wang, D. M., Deratani, A., Pochat-Bohatier, C., Lee, K. R., \& Lai, J. Y. (2006). Morphology control of polysulfone hollow fiber membranes via water vapor induced phase separation. Journal of Membrane Science, 278(12), 390-400. http://dx.doi.org/10.1016/j.memsci.2005.11.029.

18. Tsai, H. A., Lin, J. H., Wang, D. M., Lee, K. R., \& Lai, J. Y. (2006). Effect of vapor-induced phase separation on the morphology and separation performance of polysulfone hollow fiber membranes. Desalination, 200(1-3), 247-249. http://dx.doi.org/10.1016/j.desal.2006.03.313.

19. Lee, H. J., Jung, B., Kang, Y. S., \& Lee, H. (2004). Phase separation of polymer casting solution by nonsolvent vapor. Journal of Membrane Science, 245(1-2), 103-112. http://dx.doi. org/10.1016/j.memsci.2004.08.006.

20. Dai, Y., Li, Q., Ruan, X., Hou, Y., Jiang, X., Yan, X., He, G., Meng, F., \& Wang, Z. (2019). Fabrication of defect-free matrimid ${ }^{\circledR}$ asymmetric membranes and the elevated temperature application for N2/SF6 separation. Journal of Membrane Science, 577, 258265. http://dx.doi.org/10.1016/j.memsci.2019.01.050.

21. American Society for Testing and Materials - ASTM. (2000). ASTM E96-00: standard test methods for water vapor transmission of materials (pp. 907-914). West Conshohocken: ASTM. http://dx.doi.org/10.1520/E0096-00.

22. Sadrzadeh, M., \& Bhattacharjee, S. (2013). Rational design of phase inversion membranes by tailoring thermodynamics and kinetics of casting solution using polymer additives. Journal of Membrane Science, 441, 31-44. http://dx.doi.org/10.1016/j. memsci.2013.04.009. 